\title{
Prediction of In-vivo Performance of Naproxen and Esomeprazole Magnesium Delayed- Release Tablets using Biorelevant Dissolution Tests
}

\author{
Devi Thamizhanban ${ }^{1 *}$, Gampa Tulja Rani² and Kathiresan Krishnasamy \\ 'Department of Pharmacy, Annamalai University, Annamalai Nagar, Chidambaram - 608002, Tamil Nadu, \\ India; devrajmphd@gmail.com,dr.kathiresan123@rediffmail.com \\ 2Malla Reddy Pharmacy College, Maisammaguda, Hyderabad - 500014, India; tuljapharma@yahoo.com
}

\begin{abstract}
Main objective of this research work was to develop a biorelevant dissolution method by correlating the in-vivo behavior of Naproxen and Esomeprazole magnesium delayed release tablets 500/20mg, when administered orally under pre-prandial condition. The target dissolution profile for bio-relevant dissolution media was derived, by deconvoluting mean blood plasma concentration time profile of Naproxen and Esomeprazole, achieved after oral administration under pre-prandial condition. The dissolution media volume and RPM were optimized using full factorial design of experiment. The dissolution profile observed with office of generic drugs recommended dissolution media was faster in release for Naproxen part and slower in release for Esomeprazole part in comparison to target release of bio-relevant dissolution method, with the $\mathrm{F}_{2}$ value of 31 for Naproxen and 29 for Esomeprazole. USP Apparatus-I with fasted state simulated gastro intestinal change over dissolution media were used for method development. Based on ANOVA results, for Naproxen part, $250 \mathrm{ml}$ of fasting change over dissolution medium, and 50RPM, with the desirability factor of 0.508 was concluded as bio relevant dissolution medium. For esomeprazole part, the $900 \mathrm{ml}$ of fasting change over dissolution medium, and 100RPM, with the desirability factor of 0.479 was concluded as bio-relevant dissolution medium. The $\mathrm{F}_{2}$ value observed between in-vitro and in-vivo dissolution profile is 64 and 63, the regression co-efficient $\left(R^{2}\right)$ value of 0.987 and 0.997 for Naproxen and Esomeprazole respectively demonstrates a very good in-vitro/in-vivo correlation under pre-prandial condition. The developed method shall be used as a predictive in-vitro tool for evaluation Naproxen from Naproxen and Esomeprazole magnesium delayed release tablets, and also gives the advantage for claiming bio-waiver for remaining strengths.
\end{abstract}

Keywords: Bio-Relevant, Delayed Release, Esomeprazole, magnesium, Naproxen, Pre-prandial

\section{Introduction}

Naproxen and Esomeprazole magnesium delayed release tablets are used for treatment of osteoarthritis, rheumatoid arthritis and ankylosing spondylitis in adults. Naproxen and Esomeprazole magnesium is combination of proton pump inhibitor and a non steroidal anti- inflammatory drug as delayed-release tablet combining an enteric coated Naproxen core and an immediaterelease Esomeprazole magnesium layer surrounding the core. Twice a day delayed release tablets are having the oral bioavailability of $95 \%$ and $75 \%$ with the elimination half-life of approximately $15 \mathrm{hrs}$ and $1.2 \mathrm{hrs}$ for Naproxen and Esomeprazole respectively ${ }^{1}$.

${ }^{*}$ Author for correspondence 
Delayed-Release (DR) formulations are developed to avoid the degradation of drug in stomach or to avoid the irritation in gastric mucosa. The design of delayed release will alter the pharmacokinetic properties of drug. Additional clinical studies were performed to understand the rate of release vs. pharmacokinetics of drug. Hence, biorelevant dissolution method plays a critical role in determining drug product performance ${ }^{2-4}$.

Many research works were carried out on estimation of Naproxen and Esomeprazole from blood plasma and chemical characterization, using RP-HPLC. Analytical method for bio-relevant dissolution method was not studied by any researcher ${ }^{5-7}$.

Deconvolution is the process, to convert the mean plasma concentration drug profile achieved after oral administration of drug product into cumulative percentage drug release for a certain period of time. Plasma concentration will increase based on rate of absorption up to reaching the $\mathrm{C}_{\text {max }}$, and decline in concentration will be observed due to biological half-life and elimination rate of drug. Where as in dissolution cumulative percentage of drug release would be on increasing trend upto $100 \%$. Wagner-Nelson deconvolution procedure is adopted to identify the percentage of drug absorbed from drug plasma concentration-time profile, with the aid of elimination rate and half-life of the specific product ${ }^{8}$.

The quality control dissolution procedure is used to characterise the product for completeness of drug solubility in specified medium for a specified period of time from batch to batch, evaluated with regular conventional buffer with or without surfactant, using compendial dissolution apparatus, and the dissolution method is specific to the product ${ }^{9}$. The biorelevant dissolution method is used to predict the in-vivo performance of product, evaluated with biorelevant dissolution media, using either compendial or non-compendial dissolution apparatus. The dissolution media is specific to the human gastrointestinal condition and transit time. The agitation speed and media volume are required to be optimised for the product ${ }^{10-12}$.

Several physiologically based dissolution media were developed for simulating gastro intestinal condition, and are used in the present study. Analytical method was developed by using quality by design approach, and the experiments were carried out with full factorial design $\operatorname{method}^{13}$.
The correlation between percentage of drug absorbed through in-vivo study and percentage of drug released though in-vitro dissolution is established by In-Vitro/In-Vivo Correlation (IVIVC) or In-Vitro/In-Vivo Relationship $(\text { IVIVR) })^{14,15}$.

The research work is aimed to develop a biorelevant dissolution method by simulating gastro intestinal $\mathrm{pH}$ condition of pre-prandial state.

\section{Materials and Methods}

\subsection{Materials}

Vivomo ${ }^{(\mathrm{R})}$ manufactured by Horizon pharma was procured from pharmacy. Working standards for Naproxen \& Esomeprazole magnesium was obtained as gift sample from Dr. Reddy's Laboratories. Trihydroxy methyl amino methane (TRIS), Acetonitrile, Monobasic potassium phosphate, Glacial acetic acid, N-Butyl amine, Acetonitrile, Sodium perchlorate, perchloric acid, Methanol of suitable HPLC and AR grade were purchased from E. Merck Co., Mumbai. Pepsin 3000NF (Meteoric Bio Pharmaceuticals Pvt. Ltd.), Lecithin (Soya lecithin India), Glyceryl monooleate (Danisco Specialities), Maleic acid (SigmaAldrich), Sodium oleate (Riedel-de Haen), Sodium taurocholate (Prodotti Chimici), Tetrahydro furan (Merck), Pancreatin powder (Scientific Protein Laboratories LLC) were procured from indigenous vendors and used for evaluation.

\subsection{Instrumentation}

RP-HPLC system (Agilent 1200 with binary pump and UV detector), Electrolab dissolution test apparatus with paddle system (USP-II), with Japanese sinker and Dissolution apparatus USP-I (Electrolab) with reduced size vessel of $250 \mathrm{ml}$. The analysis was carried out using Agilent 1200 RP-HPLC system consisting of a pump, an injector, UV detector, with an auto sampler and column heater. Data were collected and processed using Empower software. Other instruments used for analysis were Analytical Balance, Ultrasonic Bath, Centrifuge, $\mathrm{pH}$ meter, Oven and Mechanical shaker. Rotavap (type R-114, Buechi, Essen, Germany), Polyvinyl difluoride filters (0.45 micron) used for sample filtration were purchased from Rankem, India. 


\subsection{Methods}

\subsubsection{Quality Control Dissolution Testing}

Quality control dissolution testing is the procedure generally adopted for release of every batch manufactured at commercial scale using regular buffer, which was performed as per the Office of Generic Drugs (OGD) recommended procedure. Being Esomeprazole highly degradable to acidic environment, the dissolution was performed directly on $\mathrm{pH} 7.4$ phosphate buffer, the samples were analyzed using RP-HPLC method. The standard procedures were followed for characterization as per USP. The effect of speed on dissolution was evaluated for Naproxen at 35, 50 and 75 RPM, and for Esomeprazole, at 50, 75 and 100 RPM.

\subsubsection{Biorelevant Testing}

A biorelevant dissolution media used, to simulate the preprandial condition, using USP apparatus-I, to simulate release of Naproxen and Esomeprazole magnesium delayed release tablet (Vivomo) in the GI tract. The product is recommended to administer 30 minutes before food. Hence, only fasting state simulated dissolution media was evaluated for biorelevant method development. The dissolution experimental design was executed with Design Of Experiment (DOE), using mini tab software, a full factorial design, with 2 factors of RPM at 4 levels and Media volume at 3 levels, the response was evaluated at four time points for dissolution of Naproxen, and two points for dissolution of Esomeprazole. The factor levels and response to be measured were presented in (Table 1).

The following biorelevant dissolution media were used for dissolution testing: Fasted State Simulated Gastric Fluid (FaSSGF), Fasted state simulated intestinal fluid (FaSSIF) pH 6.5, pH 7.0 and pH 7.5. The compositions and preparation of these biorelevant dissolution media have been described in various literature.

\section{Results and Discussions}

\subsection{Deconvolution of Pre-Prandial in-vivo Data}

The mean blood plasma drug concentration (Cp) of Naproxen and Esomeprazole time profiles after oral administration of VIVOMO 500/20mg at pre-prandial condition were deconvoluted using Wagner-Nelson numerical deconvolution method. The target dissolution profile was derived from fraction of drug absorbed, and the results are presented in (Table 2).

The deconvoluted data indicates that under preprandial condition $85 \%$ of Naproxen is absorbed in 4 hrs and $98 \%$ of Esomeprazole is absorbed at 30 minutes, which directs the simulated dissolution to be performed for $4 \mathrm{hrs}$ for Naproxen and 30 minutes for Esomeprazole, using appropriate dissolution sink conditions.

In-vitro dissolution of Vivomo tablets 500/20mg in OGD recommended dissolution media, and the study on effect of RPM:

A comparative dissolution profile of Vivomo tablets in OGD recommended dissolution media and target dissolution profile, along with the effect of RPM on dissolution profile are presented in (Table 3\&4) and (Figure 1\&2) and compared for similarity factor with target dissolution profile for Naproxen and Esomeprazole were presented respectively.

The dissolution profile observed from Vivomo tablets $500 / 20 \mathrm{mg}$, using office of generic drugs recommended dissolution media was not comparable to the target dissolution profile required for developing bio-relevant

Table 1. Factor information

\begin{tabular}{|c|c|c|c|c|c|c|}
\hline \multirow[b]{2}{*}{ Factors } & \multicolumn{3}{|c|}{ Naproxen part } & \multirow{2}{*}{\multicolumn{3}{|c|}{$\begin{array}{l}\text { Esomeprazole part } \\
\text { Esomeprazole part }\end{array}$}} \\
\hline & Levels & Values & Responses & & & \\
\hline \multirow{3}{*}{ RPM } & \multirow{3}{*}{4} & \multirow{3}{*}{$35,50,75 \& 100$} & \multirow{4}{*}{$\begin{array}{l}\text { Dissolution at } 1 \mathrm{hrs}, \\
2 \mathrm{hrs}, 2 \mathrm{hrs} \& 4 \mathrm{hrs}\end{array}$} & Levels & Values & Responses \\
\hline & & & & 4 & $35,50,75 \& 100$ & \multirow{3}{*}{$\begin{array}{l}\text { Dissolution at } \\
30 \mathrm{mins} \& 1 \mathrm{hr}\end{array}$} \\
\hline & & & & & & \\
\hline Volume & 3 & $\begin{array}{l}250,500 \& \\
900 \mathrm{ml}\end{array}$ & & 2 & $100 \mathrm{ml} \& 250 \mathrm{ml}$ & \\
\hline
\end{tabular}


Table 2. Target dissolution profile deconvoluted from pre-prandial In-vivo data

\begin{tabular}{|c|c|c|c|c|c|c|}
\hline \multirow[b]{2}{*}{ Time (hrs) } & \multicolumn{3}{|c|}{ Naproxen } & \multicolumn{3}{|c|}{ Esomeprazole } \\
\hline & $\begin{array}{l}\text { Mean drug plasma } \\
\text { concentration } \\
\text { in human } \\
\text { pre-prandial }) \\
\text { Cp }(\mathbf{n g} / \mathrm{mL})\end{array}$ & $\begin{array}{c}\text { Fraction } \\
\text { absorbed } \\
\text { (Numerical } \\
\text { Deconvolution } \\
\text { by Wagner- } \\
\text { Nelson method) }\end{array}$ & $\begin{array}{c}\% \\
\text { Absorbed } \\
\text { (Target } \\
\text { profile) }\end{array}$ & $\begin{array}{l}\text { Mean drug plasma } \\
\text { concentration } \\
\text { in human } \\
\text { (Pre-prandial }) \\
\text { Cp }(\mathbf{n g} / \mathrm{mL})\end{array}$ & $\begin{array}{c}\text { Fraction } \\
\text { absorbed } \\
\text { (Numerical } \\
\text { Deconvolution } \\
\text { by Wagner- } \\
\text { Nelson method) }\end{array}$ & $\begin{array}{c}\text { \% Absorbed } \\
\text { (Target profile) }\end{array}$ \\
\hline 0 & 0.00 & 0.00 & 0.00 & 0.00 & 0.00 & 0 \\
\hline 0.5 & 3.27 & 0.05 & 5 & 315.25 & 0.98 & 98 \\
\hline 1 & 10.55 & 0.17 & 17 & 180.97 & 0.93 & 93 \\
\hline 1.5 & 20.96 & 0.33 & 33 & 109.69 & 0.92 & 92 \\
\hline 2 & 34.93 & 0.56 & 56 & 72.52 & 0.93 & 93 \\
\hline 2.5 & 40.13 & 0.66 & 66 & 49.82 & 0.94 & 94 \\
\hline 3 & 43.40 & 0.72 & 72 & 33.33 & 0.95 & 95 \\
\hline 3.5 & 47.26 & 0.80 & 80 & 25.12 & 0.96 & 96 \\
\hline 4 & 49.49 & 0.85 & 85 & 16.88 & 0.97 & 97 \\
\hline 6 & 50.53 & 0.94 & 94 & 4.66 & 0.90 & 90 \\
\hline 8 & 42.65 & 0.89 & 89 & 1.74 & 0.99 & 99 \\
\hline 10 & 39.38 & 0.89 & 89 & 1.24 & 1.00 & 100 \\
\hline 12 & 35.22 & 0.88 & 88 & 0.25 & 1.00 & 100 \\
\hline
\end{tabular}

Table 3. Dissolution profile of Naproxen part from Vivomo Tablets 500/20mg in $0.1 \mathrm{~N} \mathrm{HCl}$ for $2 \mathrm{hrs}$ followed pH 6.8 Phosphate buffer for 2 hrs. USP-II, $1000 \mathrm{ml}$

\begin{tabular}{|c|c|c|c|c|}
\hline \multirow{2}{*}{ B. No. } & \multicolumn{3}{|c|}{ Vivomo 079358 } & \multirow{2}{*}{ Target profile at fasting for Naproxen } \\
\cline { 1 - 2 } Time (hrs) & 35 RPM & 50 RPM & 75 RPM & 0 \\
\hline 0 & 0.0 & 0.0 & 0.0 & 17 \\
\hline 1 & $0.4 \pm 0.2$ & $1.4 \pm 0.2$ & $1.6 \pm 0.2$ & 56 \\
\hline 2 & $3.9 \pm 0.5$ & $5.8 \pm 0.6$ & $5.2 \pm 0.4$ & 66 \\
\hline 2.5 & $38.1 \pm 2.5$ & $57.2 \pm 0.4$ & $56.4 \pm 1.7$ & 72 \\
\hline 3 & $75.0 \pm 0.6$ & $76.6 \pm 0.7$ & $79.8 \pm 1.4$ & 80 \\
\hline 3.5 & $98.8 \pm 0.6$ & $100.2 \pm 0.4$ & $100.6 \pm 0.5$ & 85 \\
\hline 4 & $100.0 \pm 0.2$ & $100.5 \pm 0.3$ & $100.6 \pm 0.5$ & \\
\hline
\end{tabular}


Table 4. Dissolution profile of Esomeprazole part from Vivomo tablets 500/20mg in pH 7.4 Phosphate buffer for 2 hrs USP-II, $900 \mathrm{ml}$

\begin{tabular}{|c|c|c|c|c|}
\hline B. No. & \multicolumn{3}{|c|}{ Vivomo 079358 } & \multirow{2}{*}{ Target profile at fasting for Esome prazole } \\
\hline Time (hrs) & $\mathbf{5 0 ~ R P M}$ & $\mathbf{7 5 ~ R P M}$ & 100RPM & 0 \\
\hline 0 & 0.0 & 0 & 0.0 & 98 \\
\hline 0.5 & $34.6 \pm 1.5$ & $46.0 \pm 0.4$ & $50.7 \pm 0.8$ & 93 \\
\hline 1 & $86.5 \pm 1.7$ & $93.4 \pm 1.7$ & $93.5 \pm 0.8$ & 92 \\
\hline 1.5 & $99.1 \pm 0.8$ & $99.9 \pm 0.9$ & $100.2 \pm 0.3$ & 93 \\
\hline 2 & $100.3 \pm 0.2$ & $99.6 \pm 0.2$ & $100.4 \pm 0.2$ & \\
\hline \multicolumn{5}{|c|}{ Note: mean \pm SD, $\mathrm{n}=3$} \\
\hline
\end{tabular}

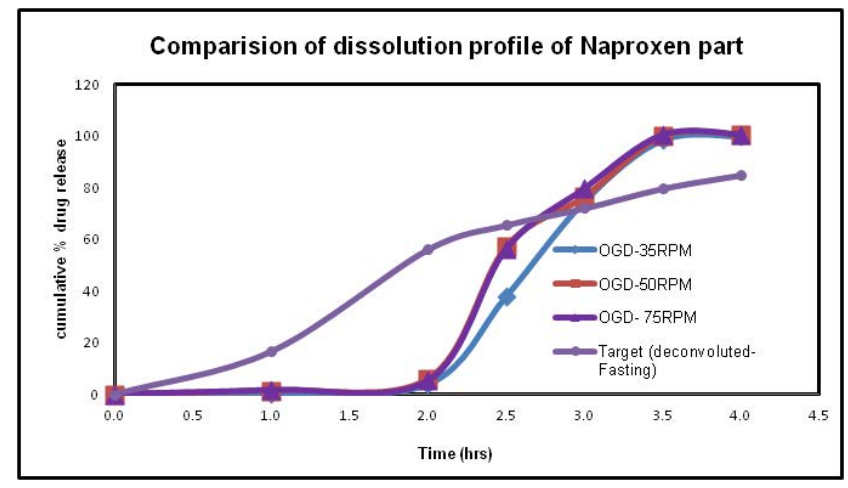

Figure 1. Comparison of dissolution profile of Naproxen from Vivomo in OGD recommended dissolution media at different RPM with target dissolution profile (deconvoluted from In-vivo).

dissolution method. The change is RPM of dissolution was not having any significant impact on dissolution profile the similarity factor $\left(\mathrm{F}_{2}\right)$ values observed also below $50 \%$. Hence, it was decided to develop a bio-predictive dissolution method to simulate the in-vivo performance of drug product.

\subsection{Development of Bio-Relevant Dissolution Method}

The dissolution method was developed using a quality by design approach. The variables in dissolution method are dissolution apparatus, dissolution media, dissolution media volume and agitation speed. For each factor, risk assessment was preformed and, based on the risk assessment, dissolution media volume and agitation speed is required to be optimized. The risk assessment was presented in (Table 5), and Risk Priority Number (RPN) was derived based on risk assessment.

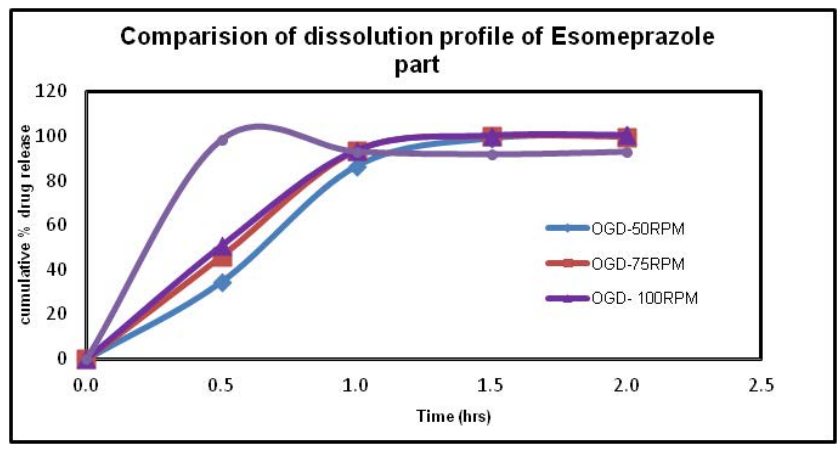

Figure 2. Comparison of dissolution profile of Esomeprazole from VIVOMO in OGD recommended dissolution media at different RPM with target dissolution profile (deconvoluted from In-vivo).

Risk assessment measured in 3 categories, low (1), medium (2) \& high (3). The Risk number is the multiplication of all the three. The risk numbers more than 9 will be considered for DOE study. A complete full factorial design was established using minitab software, for two variables of media volume and agitation speed (RPM), and the parameters are optimized with the response factor of dissolution, at various time intervals.

The response was considered as cumulative percentage drug release at $1 \mathrm{hr}, 2 \mathrm{hrs}$, $3 \mathrm{hrs}$ and $4 \mathrm{hrs}$ time interval for Naproxen part, 30 minutes and $1 \mathrm{hr}$ time interval for Esomeprazole part of naproxen and esomeprazole magnesium delayed release tablets 500/20mg. A full factorial study with variables for bio-relevant dissolution method was presented in (Table 6) for Naproxen part and (Table 7) for Esomeprazole part along with the dissolution as response.

Main effects and interaction effect of RPM and dissolution media volume on dissolution profile of naproxen part from delayed release tablets of Naproxen 
Table 5. Risk assessment for media volume and DPM for the product

\begin{tabular}{|c|c|c|c|c|l|}
\hline Factors & Severity & Probability & Delectability & $\begin{array}{c}\text { Risk } \\
\text { Number }\end{array}$ & Justification \\
\hline $\begin{array}{c}\text { Dissolution } \\
\text { apparatus }\end{array}$ & 2 & 1 & 2 & 4 & $\begin{array}{l}\text { The most suitable apparatus for delayed release tablet is USP } \\
\text { apparatus -1 (basket) or apparatus -2 (paddle) with sinker. } \\
\text { Apparatus-1 is selected for dissolution method, hence risk is } \\
\text { low. }\end{array}$ \\
\hline $\begin{array}{c}\text { Dissolution } \\
\text { media }\end{array}$ & 1 & 2 & 2 & 4 & $\begin{array}{l}\text { The dissolution media selected is based on human gastro } \\
\text { intestinal condition and transit time. Hence, the risk is very } \\
\text { low. }\end{array}$ \\
\hline $\begin{array}{c}\text { Media } \\
\text { volume }\end{array}$ & 3 & 3 & 3 & 27 & $\begin{array}{l}\text { Dissolution media volume is directly related to intrinsic } \\
\text { solubility of drug, hence the risk is high. }\end{array}$ \\
\hline RPM & 3 & 3 & 2 & $\begin{array}{l}\text { The agitation speed disrupts the structure to have faster } \\
\text { erosion of pellets. Hence the risk is high. }\end{array}$ \\
\hline
\end{tabular}

Table 6. A Full factorial study and responses of the factors for Naproxen part at pre-prandial (Fasting) state simulating dissolution method

\begin{tabular}{|c|c|c|c|c|c|c|}
\hline \multirow{2}{*}{ Run order } & \multicolumn{2}{|c|}{ Factors } & \multicolumn{4}{|c|}{ Responses } \\
\hline & RPM & Volume & Dissolution $1 \mathrm{hr}$ & Dissolu-tion 2 hrs & Dissolution 3 hrs & Dissolution 4 hrs \\
\hline 1 & 35 & 900 & $7.5 \pm 0.9$ & $77.0 \pm 1.4$ & $99.3 \pm 0.3$ & $100.4 \pm 0.2$ \\
\hline 2 & 50 & 900 & $7.6 \pm 0.5$ & $80.3 \pm 0.2$ & $100.4 \pm 0.2$ & $100.2 \pm 0.2$ \\
\hline 3 & 75 & 900 & $7.3 \pm 0.2$ & $79.6 \pm 0.2$ & $99.9 \pm 0.4$ & $99.8 \pm 0.4$ \\
\hline 4 & 100 & 900 & $8.1 \pm 0.5$ & $79.4 \pm 1.2$ & $100.0 \pm 0.4$ & $99.9 \pm 0.5$ \\
\hline 5 & 35 & 500 & $5.6 \pm 0.5$ & $65.5 \pm 0.9$ & $88.7 \pm 0.2$ & $100.2 \pm 0.4$ \\
\hline 6 & 50 & 500 & $5.9 \pm 0.5$ & $67.3 \pm 0.9$ & $90.4 \pm 0.7$ & $99.9 \pm 0.3$ \\
\hline 7 & 75 & 500 & $6.4 \pm 0.2$ & $69.9 \pm 0.2$ & $90.6 \pm 0.5$ & $99.8 \pm 0.1$ \\
\hline 8 & 100 & 500 & $6.8 \pm 0.3$ & $71.9 \pm 0.7$ & $92.2 \pm 0.6$ & $99.3 \pm 0.7$ \\
\hline 9 & 35 & 250 & $3.3 \pm 0.4$ & $46.5 \pm 0.7$ & $66.9 \pm 1.2$ & $82.6 \pm 0.7$ \\
\hline 10 & 50 & 250 & $4.5 \pm 0.3$ & $55.0 \pm 0.7$ & $73.4 \pm 0.8$ & $86.6 \pm 0.7$ \\
\hline 11 & 75 & 250 & $5.2 \pm 0.4$ & $60.0 \pm 1.2$ & $79.4 \pm 0.9$ & $90.6 \pm 0.5$ \\
\hline 12 & 100 & 250 & $5.6 \pm 0.5$ & $66.1 \pm 0.4$ & $85.6 \pm 0.9$ & $97.8 \pm 1.1$ \\
\hline
\end{tabular}

Note: mean $\pm S D, n=3$ 
and Esomeprazole magnesium were presented in (Figure 3). ANOVA results and model summary were presented in (Table 8) for Naproxen part, which concludes the model is significant.

The multiple response graph presented in (Figure 4), indicates the predicted bio-relevant dissolution method for Naproxen part from the delayed release dosage form is $50 \mathrm{RPM}$ and $250 \mathrm{ml}$ of change over dissolution media, with the composite desirability of 0.508 . For all DOE data analysis, the commonly used alpha of 0.05 was chosen to differentiate between significant and not significant factors.

Main effects and interaction effect of RPM and dissolution media volume on dissolution profile of Esomeprazole part from delayed release tablets of Naproxen and Esomeprazole magnesium were presented in (Figure 5). ANOVA results and model summary were presented in (Table 9) for Esomeprazole part, which concludes the model is significant.

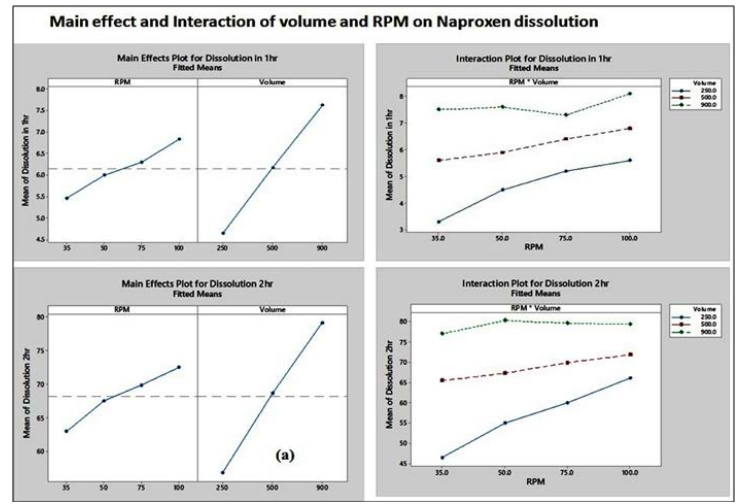

a

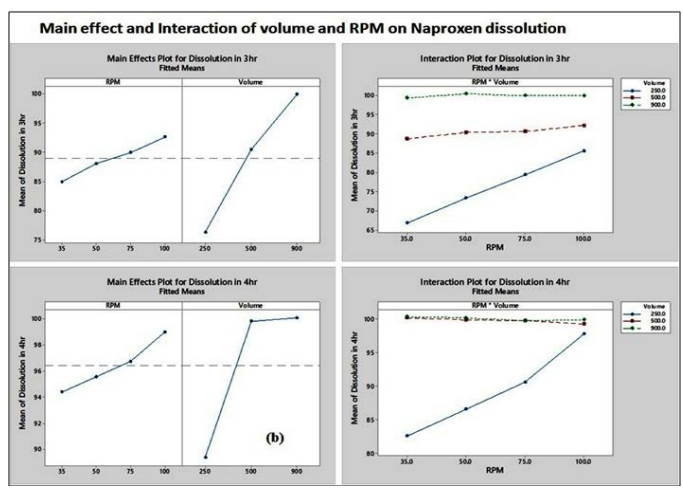

$\mathrm{b}$

Figure 3. Main effect and interaction effect on RPM and media volume on dissolution profile of Naproxen part under pre-prandial condition: (a) at $1 \mathrm{hr} \&$ $2 \mathrm{hrs}$, and (b) 3 hrs \& 4 hrs..

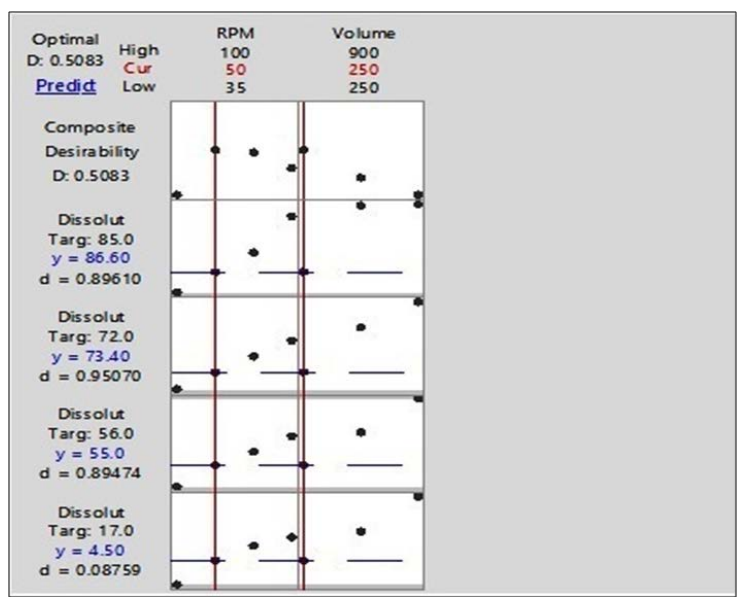

Figure 4. Response optimization for dissolution of Naproxen from Vivomo in fasting condition at 1 hr, 2 hrs, 3 hrs and 4 hrs.

The multiple response graph presented in (Figure 6), indicates the predicted bio-relevant dissolution method for Esomeprazole part from the delayed release dosage form is $100 \mathrm{RPM}$ and $900 \mathrm{ml}$ of $\mathrm{pH} 7.4$ phosphate buffer, with the composite desirability of 0.479 . Main effects and interaction effect of RPM and dissolution media volume on dissolution profile of Esomeprazole part from delayed release tablets of naproxen and esomeprazole magnesium were presented in (Figure 6). Based on the above results the target dissolution profile for biorelevant dissolution method has been finalized, lower and upper limits are derived using minitab, with $95 \%$ confidence interval, and the values are presented in (Table 10), for both Esomeprazole part and Naproxen part of delayed release formulation of Naproxen and Esomeprazole delayed release tablets.

\subsection{Establishment of the IVIVR}

A comparative dissolution profile using USP apparatus -I, with $250 \mathrm{ml}$ of dissolution medium, and $50 \mathrm{RPM}$ established for biorelevant dissolution method and target profile at pre-prandial condition for Naproxen part is presented in (Table 11) and (Figure 7\&8).

Percentage of drug absorbed obtained from deconvoluted in-vivo data was compared with percentage of drug dissolved under simulated fasting condition, and the $\mathrm{F}_{2}$ value is 64 .

The fraction of drug released in-vitro is consistently comparable to the fraction of drug released in-vivo indicating discriminating dissolution conditions. The regression co-efficient $\left(\mathrm{R}^{2}\right)$ value of 0.987 also indicates very good predictive capability of the relationship. 
Table 7. A Full factorial study and Response of the factors for Esomeprazole part at pre-prandial (Fasting) state simulating dissolution method

\begin{tabular}{|c|c|c|c|c|}
\hline \multirow{2}{*}{ Run order } & \multicolumn{2}{|c|}{ Factors } & \multicolumn{2}{|c|}{ Response } \\
\hline & RPM & Volume & Dissolution 30 minutes & Dissolution $1 \mathrm{hr}$ \\
\hline 1 & 35 & 900 & $91.7 \pm 1.4$ & $100.3 \pm 0.2$ \\
\hline 2 & 50 & 900 & $96.5 \pm 1.5$ & $100.2 \pm 0.4$ \\
\hline 3 & 75 & 900 & $99.5 \pm 0.4$ & $100.2 \pm 0.3$ \\
\hline 4 & 100 & 900 & $100.1 \pm 0.5$ & $100.9 \pm 0.3$ \\
\hline 5 & 35 & 500 & $83.9 \pm 1.6$ & $100.5 \pm 0.3$ \\
\hline 6 & 50 & 500 & $85.2 \pm 0.5$ & $100.6 \pm 0.2$ \\
\hline 7 & 75 & 500 & $90.5 \pm 0.3$ & $100.3 \pm 0.5$ \\
\hline 8 & 100 & 500 & $95.2 \pm 0.8$ & $99.8 \pm 0.4$ \\
\hline 9 & 35 & 250 & $75.8 \pm 0.5$ & $95.2 \pm 0.4$ \\
\hline 10 & 50 & 250 & $78.3 \pm 0.4$ & $98.8 \pm 0.4$ \\
\hline 11 & 75 & 250 & $80.9 \pm 0.7$ & $100.1 \pm 0.5$ \\
\hline 12 & 100 & 250 & $86.5 \pm 3.5$ & $100.1 \pm 0.5$ \\
\hline
\end{tabular}

Note: mean $\pm S D, n=3$

Table 8. ANOVA results for design of experiment for Naproxen part

\begin{tabular}{|c|c|c|c|c|c|c|c|c|c|}
\hline \multirow[b]{2}{*}{ Source } & \multirow[b]{2}{*}{$\begin{array}{c}\text { Degrees of } \\
\text { freedom }\end{array}$} & \multicolumn{2}{|c|}{ Dissolution at $1 \mathrm{hr}$} & \multicolumn{2}{|c|}{ Dissolution at $2 \mathrm{hrs}$} & \multicolumn{2}{|c|}{ Dissolution at $3 \mathrm{hrs}$} & \multicolumn{2}{|c|}{ Dissolution at $4 \mathrm{hrs}$} \\
\hline & & $\begin{array}{l}\text { Adjusted } \\
\text { sum } \\
\text { square }\end{array}$ & $\begin{array}{c}\text { Adjusted } \\
\text { mean } \\
\text { square }\end{array}$ & $\begin{array}{l}\text { Adjusted } \\
\text { sum } \\
\text { square }\end{array}$ & $\begin{array}{c}\text { Adjusted } \\
\text { mean } \\
\text { square }\end{array}$ & $\begin{array}{l}\text { Adjusted } \\
\text { sum } \\
\text { square }\end{array}$ & $\begin{array}{c}\text { Adjusted } \\
\text { mean } \\
\text { square }\end{array}$ & $\begin{array}{l}\text { Adjusted } \\
\text { sum } \\
\text { square }\end{array}$ & $\begin{array}{c}\text { Adjusted } \\
\text { mean } \\
\text { square }\end{array}$ \\
\hline Model & 11 & 21.95 & 2.00 & 1220.71 & 110.97 & 1326.08 & 120.55 & 422.98 & 38.45 \\
\hline Linear & 5 & 20.64 & 4.13 & 1129.70 & 225.94 & 1219.43 & 243.89 & 330.94 & 66.19 \\
\hline DPM & 3 & 2.94 & 0.98 & 145.07 & 48.36 & 92.98 & 30.99 & 34.69 & 11.56 \\
\hline Vol. & 2 & 17.71 & 8.85 & 984.63 & 492.32 & 1126.45 & 563.22 & 296.26 & 148.13 \\
\hline $\begin{array}{c}\text { 2-Way } \\
\text { Interaction }\end{array}$ & 6 & 1.31 & 0.22 & 91.01 & 15.17 & 106.66 & 17.78 & 92.04 & 15.34 \\
\hline $\mathrm{RPM}^{\star}$ Volume & 6 & 1.31 & 0.22 & 91.01 & 15.17 & 106.66 & 17.78 & 92.04 & 15.34 \\
\hline
\end{tabular}


Table 9. ANOVA results for design of experiment for Esomeprazole part

\begin{tabular}{|c|c|c|c|c|c|}
\hline \multirow{2}{*}{ Source } & \multirow{2}{*}{$\begin{array}{c}\text { Degrees } \\
\text { of } \\
\text { freedom }\end{array}$} & Adjusted sum square & Adjusted mean square & Adjusted sum square & Adjusted mean square \\
\cline { 3 - 6 } & 11 & 737.46 & 67.04 & 25.47 & 2.32 \\
\hline Model & 5 & 723.73 & 144.75 & 13.63 & 2.73 \\
\hline Linear & 2 & 549.46 & 274.73 & 8.66 & 4.33 \\
\hline DPM & 3 & 174.27 & 58.09 & 4.97 & 1.66 \\
\hline Vol. & 6 & 13.73 & 2.29 & 11.84 & 1.97 \\
\hline $\begin{array}{c}2-W a y \\
\text { Interactions }\end{array}$ & 6 & 13.73 & 2.29 & 11.84 & 1.97 \\
\hline $\begin{array}{c}\text { DPM } \\
\text { Volume }\end{array}$ & & & & \\
\hline
\end{tabular}

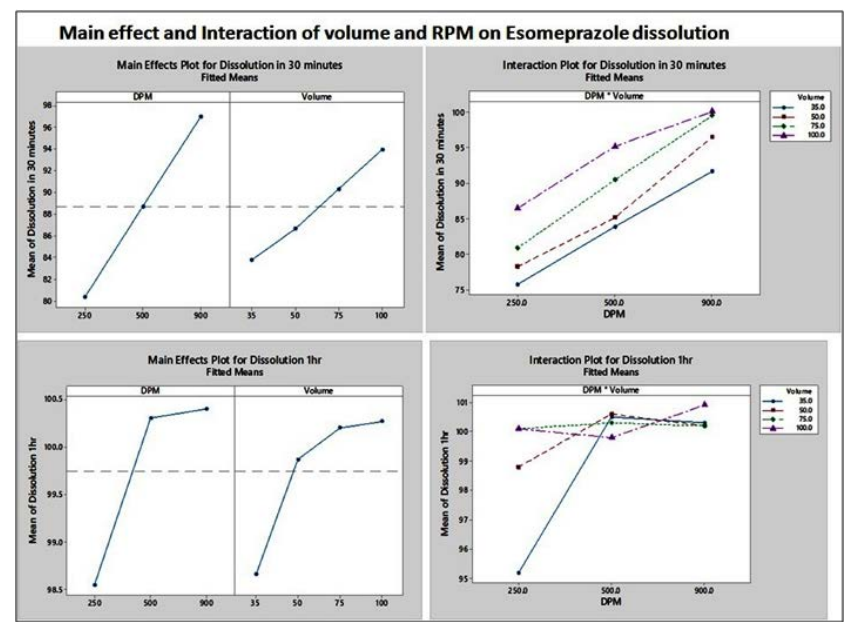

Figure 5. Main effect and interaction effect on RPM and media volume on dissolution profile of Esomeprazole part under pre-prandial condition.

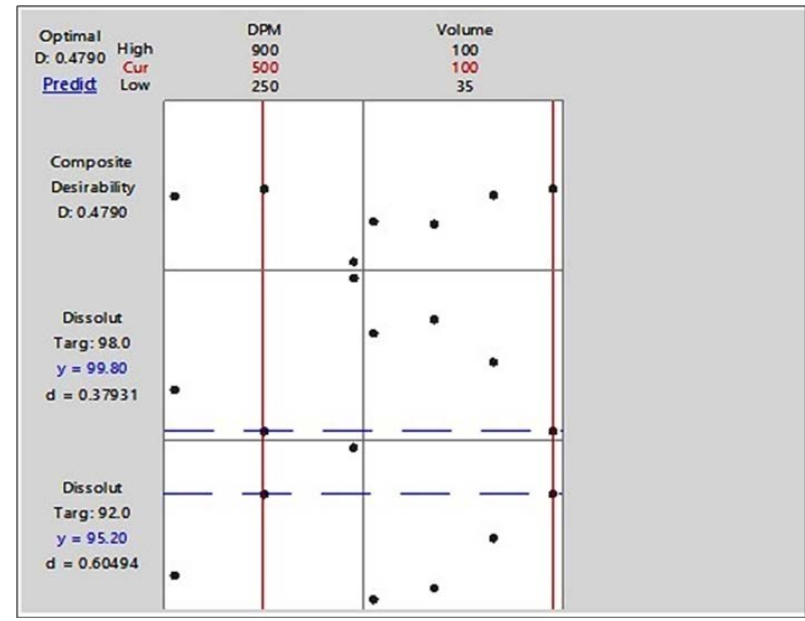

Figure 6. Response optimisation for dissolution of Esomeprazole from Vivomo in fasting condition at 30 minutes and 1 hour.

Table 10. Target and ranges recommended for Naproxen and Esomeprazole simulating biorelevant dissolution study

\begin{tabular}{|c|c|c|c|c|c|c|c|}
\hline \multirow{2}{*}{ Response } & \multirow{2}{*}{ Goal } & \multicolumn{3}{|c|}{ Naproxen part } & \multicolumn{3}{|c|}{ Esomeprazole part } \\
\hline & & Lower & Target & Upper & Lower & Target & Upper \\
\hline Dissolution 4 hours & Target & 82.6 & 85 & 100.4 & - & - & - \\
\hline Dissolution 3 hours & Target & 66.9 & 72 & 100.4 & - & - & - \\
\hline Dissolution 2 hours & Target & 46.5 & 56 & 80.3 & - & - & - \\
\hline Dissolution 1 hour & Target & 3.3 & 17 & 18.7 & 82.8 & 92 & 100.9 \\
\hline Dissolution 30 minutes & Target & - & - & - & 75.8 & 98 & 100.1 \\
\hline
\end{tabular}


Table 11. In-Vitro and In-Vivo dissolution of Naproxen part of VIVOMO at preprandial (Fasting) condition

\begin{tabular}{|c|c|c|c|}
\hline $\begin{array}{c}\text { Dissolution } \\
\text { (time) }\end{array}$ & $\begin{array}{c}\text { Cumulative } \\
\text { dissolution } \\
\text { time }\end{array}$ & $\begin{array}{c}\text { Cumulative } \\
\text { \% drug } \\
\text { Release }\end{array}$ & $\begin{array}{c}\text { Target } \\
\text { profile }\end{array}$ \\
\hline $\begin{array}{c}\text { FaSSGF pH 1.6 } \\
\text { for 60 minutes }\end{array}$ & 1 hour & $4.5 \pm 0.3$ & 17 \\
\hline $\begin{array}{c}\text { pH 6.5 FASSIF } \\
\text { for 60 minutes }\end{array}$ & 2 hours & $55.0 \pm 0.7$ & 56 \\
\hline $\begin{array}{c}\text { pH 7.0 Half- } \\
\text { FaSSIF for 60 } \\
\text { minutes }\end{array}$ & 3 hours & $73.4 \pm 0.8$ & 72 \\
\hline $\begin{array}{c}\text { pH 7.5 FaSSIF- } \\
\text { sans for 60 } \\
\text { minutes }\end{array}$ & 4 hours & $86.6 \pm 0.7$ & 85 \\
\hline F & & $\mathbf{6 4}$ & \\
\hline
\end{tabular}

Note: mean $\pm S D, n=3$

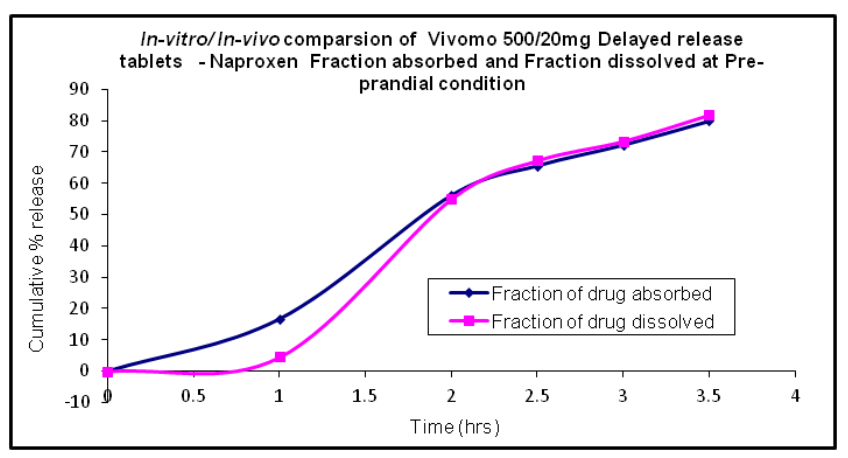

Figure 7. In-vitro/In-vivo comparison of Naproxen from Vivomo tablets 500/20mg- on fraction of drug absorbed by in-vivo and fraction of drug dissolved by in-vitro.

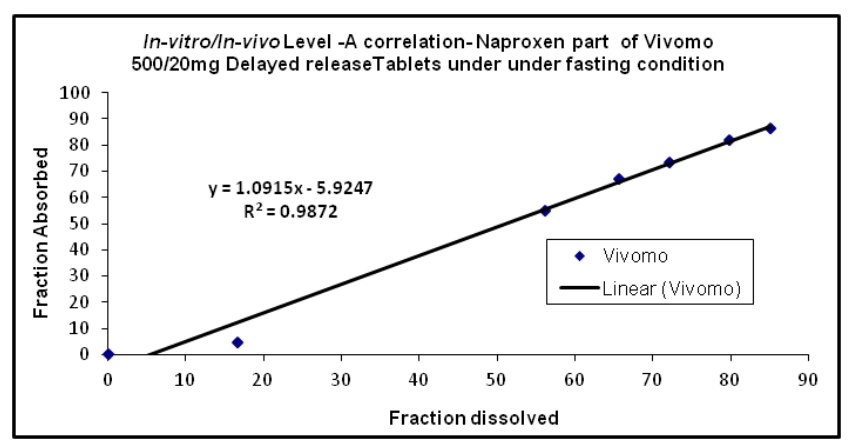

Figure 8. In-vitro/In-vivo level -A correlation- Naproxen part of Vivomo 500/20mg delayed release tablets under fasting condition.
Table 12. In-Vitro and In-Vivo dissolution of Esomeprazole part of VIVOMO at preprandial (fasting) condition

\begin{tabular}{|c|c|c|c|}
\hline $\begin{array}{c}\text { Dissolution } \\
\text { (time) }\end{array}$ & $\begin{array}{c}\text { Cumulative } \\
\text { dissolution } \\
\text { time }\end{array}$ & $\begin{array}{c}\text { Cumulative \% } \\
\text { drug Release }\end{array}$ & $\begin{array}{c}\text { Target } \\
\text { profile }\end{array}$ \\
\hline $\begin{array}{c}\text { pH 6.5 FASSIF } \\
\text { for 30 minutes }\end{array}$ & 30 minutes & $100.1 \pm 0.5$ & 98 \\
\hline $\begin{array}{c}\text { pH 6.5 FASSIF } \\
\text { for 60 minutes }\end{array}$ & 60 minutes & $100.9 \pm 0.3$ & 93 \\
\hline $\mathbf{F}_{2}$ & & $\mathbf{6 3}$ & \\
\hline
\end{tabular}

Note: mean \pm SD, $n=3$

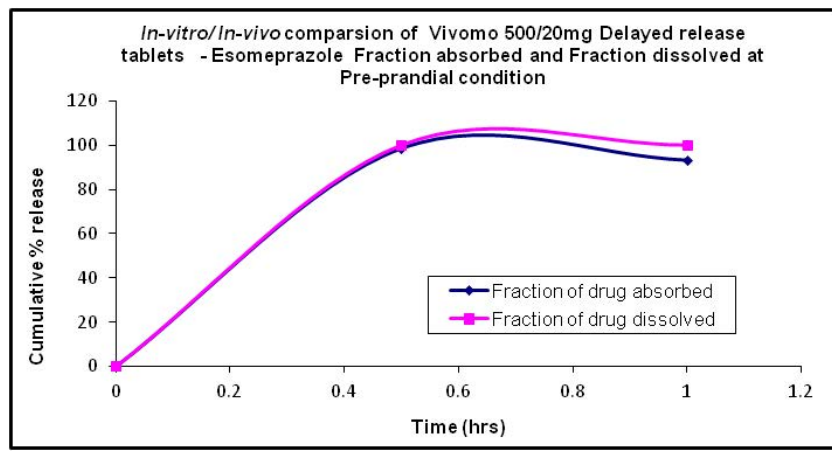

Figure 9. In-Vitro/In-Vivo comparison of Esomeprazole part from Vivomo tablets 500/20mg - on fraction of drug absorbed by In-Vivo and fraction of drug dissolved by In-Vitro.

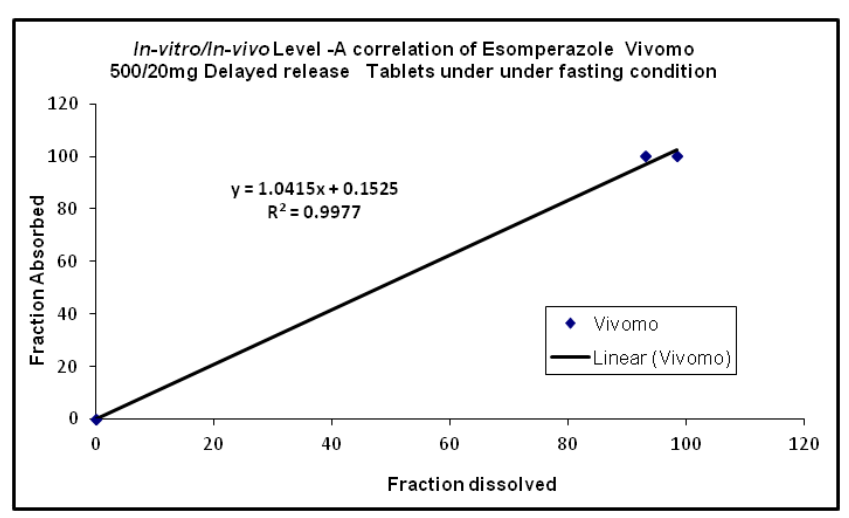

Figure 10. In-vitro/In-vivo level-A correlation-Esomeprazole part of Vivomo 500/20mg delayed release tablets under fasting condition.

A comparative dissolution profile using USP apparatus -I, with $900 \mathrm{ml}$ of dissolution medium, and $100 \mathrm{RPM}$ established for biorelevant dissolution method and target profile at pre-prandial condition for Esomeprazole part is presented in (Table 12) and (Figure 9\&10). 
Percentage of drug absorbed obtained from deconvoluted in-vivo data was compared with percentage of drug dissolved under simulated fasting condition, and the $\mathrm{F}_{2}$ value is 63 .

The fraction of drug released in-vitro is consistently comparable to the fraction of drug released in-vivo indicating over-discriminating dissolution conditions. The regression co-efficient $\left(\mathrm{R}^{2}\right)$ value of 0.997 also indicates very good predictive capability of the relationship.

\section{Conclusion}

Biorelevant dissolution method developed using USP apparatus-I, coupled with a deconvolution approach successfully correlating the in-vivo performance of Naproxen and Esomeprazole delayed release tablets after oral administration under the fasted state. Among the dissolution methods studied, $250 \mathrm{ml}$ of change over media with 50 RPM, was closest to the target under fasted state for Naproxen part, and $900 \mathrm{ml} \mathrm{pH} 6.5$ fasted state simulated change over media with 100 RPM, was closest to the target under fasted state for Esomeprazole part, based on the established IVIVC, where regression co-efficient was close to 1.0.

\section{Acknowledgement}

Authors are thankful to Malla Reddy Pharmacy College, Hyderabad and Dr. Reddy's laboratories for providing all necessary facilities for conducting the study.

\section{References}

1. US Food and Drug Administration, Silver Spring, MD 20993, Center for Drug Evaluation and Research, 2010, Printed Labeling for Vimovo (naproxen/esomeprazole magnesium) Delayed Release Tablets 30th April 2010. Cited 2018 April 5. https://www.accessdata.fda.gov/drugsatfda_ docs/nda/2010/022511Orig1s000Lbl.pdf.

2. Gaurav Gujral, Devesh Kapoor, Manish Jaimini. An updated review on modified release tablets. Journal of Drug Delivery and Therapeutics. 2018; 8(4):5-9. https:// doi.org/10.22270/jddt.v8i4.1722.

3. Heyam Saad Ali, Rasha Saad Suliman, Babiker MA Elhaj, Raina Suliman, The effect of modified release dosage forms on absorption of medications. International Journal of Pharmaceutical and Clinical Research. 2019; 11(1): 30-33.

4. Bhagat Nitin B, Yadav Adhikrao V, Mali Sachin S, Khutale Rohan A, Hajare Ashok A, Salunkhe Sachin S, Nadaf Sameer
J. A review on development of biorelevant dissolution medium. Journal of Drug Delivery and Therapeutics. 2014; 4(2):140-48. https://doi.org/10.22270/jddt.v4i2.800.

5. Bhavyasri K, Murali Balaram V, Nageswarao R, Rambabu D, Ajitha M. Rapid simultaneous determination of naproxen and esomeprazole magnesium in combined tablets by validated ultra performance liquid chromatographic method. Journal of Chemical and Pharmaceutical Research. 2013; 5(12):1230-36.

6. Palavai Sripal Reddy, Shakil Sait, Vasudevmurthy G, Vishwanath B, Prasad V, Jayapal Reddy S. Stability indicating simultaneous estimation of assay method for naproxen and esomeprazole in pharmaceutical formulations by RP-HPLC. Scholars Research Library Der Pharma Chemica. 2011; 3(6):553-64.

7. Jain DK, Jain N, Charde R. The RP-HPLC method for simultaneous estimation of Esomeprazole and Naproxen in binary combination. Pharmaceutical Methods. 2011; 2(3):167-72. https://doi.org/10.4103/2229-4708.90356. PMid: 23781450, PMCid: PMC3658060.

8. Khawla Rashee, Wagner-Nelson and Numerical Deconvolution based approaches for In-Vivo performance prediction. International Journal of Science and Research (IJSR). 2018; 7(8):1646-49. https://pdfs.semanticscholar.org/a8e8/63e064d9395e0 d71ddea9632e45271474e0b.pdf.

9. US Food and Drug Administration, Silver Spring, MD 20993, Center for Drug Evaluation and Research, 2010, Clinical Pharmacology and Biopharmaceutics Review(S), for Vimovo (naproxen/esomeprazole magnesium) delayed release tablets 30th April 2010. Cited 5 April 2018. https:// www.accessdata.fda.gov/drugsatfda_docs/nda/2010/02251 1Orig1s000ClinPharmR.pdf.

10. Andreas CJ, Chen YC, Markopoulos C, Reppas C, Dressman J. In-vitro biorelevant models for evaluating modified release mesalamine products to forecast the effect of formulation and meal intake on drug release. Eur. J. Pharm. Biopharm., 2015; 97(Pt A): 39-50. https://doi.org/10.1016/j.ejpb.2015.09.002. PMid: 26391972.

11. Jantratid E, Janssen N. Dissolution media simulating conditions in the proximal human gastrointestinal tract: An update. Pharm Res. 2008; 25(7):1663-76. https://doi. org/10.1007/s11095-008-9569-4. PMid: 18404251.

12. Sandra Klein. The use of Biorelevant dissolution media to forecast the In-Vivo performance of a drug. American Association of Pharmaceutical Scientists. 2010; 12(3):397406. https://doi.org/10.1208/s12248-010-9203-3. PMid: 20458565, PMCid: PMC2895438.

13. Ramalingam Peraman, Kalva Bhadraya, Yiragamreddy Padmanabha Reddy, Analytical quality by design: A tool for regulatory flexibility and robust analytics. International 
Journal of Analytical Chemistry. 2015; 1-9. https://doi. org/10.1155/2015/868727. PMid: 25722723, PMCid: PMC4332986.

14. FDA. Guidance for Industry. Extended Release Oral Dosage Forms: Development, Evaluation, and Application of in Vitro/In-vivo Correlations. US Department of Health and Human Services, Food and Drug Administration, Centre for Drug Evaluation and Research (CDER); 1997. https:// www.fda.gov/downloads/drugs/guidances/ucm070239. pdf.

15. Suarez-Sharp S, Li M, Duan J, Shah H, Seo P. Regulatory experience with In-Vivo In-Vitro Correlations (IVIVC) in new drug applications. American Association of Pharmaceutical Scientists. 2016; 18(6):1379-90. https://doi. org/10.1208/s12248-016-9966-2. PMid: 27480319. 